\title{
The relationship between the COPD Assessment Test score and airflow limitation in Japan in patients aged over 40 years with a smoking history
}

This article was published in the following Dove Press journal:

International Journal of COPD

9 December 2014

Number of times this article has been viewed

\section{Daisuke Yoshimoto' \\ Yasutaka Nakano² \\ Katsuya Onishi ${ }^{3}$ \\ Gerry Hagan ${ }^{4}$ \\ Paul Jones ${ }^{5}$}

'GlaxoSmithKline, Tokyo, ${ }^{2}$ Division of Respiratory Medicine, Department of Medicine, Shiga University of Medical Science, Otsu, ${ }^{3}$ Onishi Heart Clinic, Tsu, Japan; ${ }^{4}$ Independent consultant, Marbella, Spain; ${ }^{5}$ Division of Clinical Science, St George's Hospital, University of London, London, UK

Correspondence: Paul Jones

Division of Clinical Science, St George's Hospital, University of London,

London, UK

Tel +44208672 9944

Email pjones@sgul.ac.uk
Background: A large number of chronic obstructive pulmonary disease (COPD) patients in Japan remain undiagnosed, primarily due to the underuse of spirometry. Two studies were conducted to see whether the COPD Assessment Test (CAT) in primary care has the potential to identify those patients who need spirometry for a diagnosis of COPD and to determine whether patients with cardiovascular disease had airflow limitation, which could be detected by CAT.

Materials and methods: Two multicenter, noninterventional, prospective studies (studies 1 and 2) were conducted across Japan. Patients in both studies were $\geq 40$ years old with a smoking history. Those in study 1 were seen in primary care and had experienced repeated respiratory tract infections, but had no diagnosis of COPD. Patients in study 2 were identified in cardiovascular disease clinics when routinely visiting for their cardiovascular disease. All patients completed the CAT prior to lung-function testing by hand-held spirometry. The presence of airflow limitation was defined as a forced expiratory volume in 1 second $\left(\mathrm{FEV}_{1}\right) / \mathrm{FEV}_{6}$ ratio $<0.73$.

Results: A total of 3,062 subjects completed the CAT (2,067 in study 1, 995 in study 2); 88.8\% were male, and the mean age ( \pm standard deviation) was $61.5 \pm 11.6$ years. Airflow limitation was found in 400 (19.4\%) patients in study 1 , and 269 (27.0\%) in study 2 . The CAT score in patients with airflow limitation was significantly higher than in patients without airflow limitation in both studies: 8.6 (95\% confidence interval [CI] 7.9-9.2) versus 7.4 (95\% CI 7.1-7.6) in study 1 , and 8.3 (95\% CI 7.5-9.2) versus 6.4 (95\% CI 6.0-6.8) in study 2 (both $P<0.001$ ).

Conclusion: These findings suggest that the CAT has the potential to identify patients with cardiovascular disease or a history of frequent chest infections who need spirometry to diagnose COPD.

Keywords: COPD, CAT, spirometry, airflow limitation

\section{Introduction}

The prevalence of chronic obstructive disease (COPD) is expected to increase throughout the world..$^{1-3}$ There are few data available on the prevalence of airflow limitation in Japan. The prevalence of airflow limitation has been reported to range from $10.9 \%$ in the NICE study to $13.9 \%$ in another study. ${ }^{5}$ There is, however, a significant underdiagnosis of COPD in Japan, because of insufficient use of spirometry ${ }^{6}$ and also underrecognition by physicians, so these figures are likely to be underestimates. ${ }^{4}$ The high prevalence of smoking coupled with an aging population threatens to further increase the burden of COPD, highlighting the need for enhanced screening efforts and interventions for prevention and treatment. ${ }^{4}$ Previous data have shown that screening spirometry during medical checkups can identify many COPD patients not aware of this disease. ${ }^{7}$ The study using a hand-held spirometer showed that underdiagnosis of 
COPD was particularly a problem in patients with chronic bronchitis and in younger patients, ${ }^{8}$ a phenotype that is not usually recognized as COPD in Japan.

The diagnosis of COPD requires measurement of forced expiratory volume in 1 second $\left(\mathrm{FEV}_{1}\right)^{1}$. However, as COPD can affect health status independently of the level of airflow limitation, ${ }^{9}$ questionnaires have been developed to assess the impact of COPD on health status. The COPD Assessment Test (CAT) was developed as a simple tool for assessing the impact of COPD on health status that can easily be used in primary care. ${ }^{10,11}$ It is an eight-item questionnaire documenting the subject's evaluation of symptoms and their impact.

The aim of this paper was to test whether the CAT could be a useful tool to find subjects who should have spirometry to assess whether they have COPD. This could potentially improve the uptake of spirometry in the clinic by promising a higher success rate of diagnosis than random use of spirometry in smokers. It could also lead to a simple way for patients to check their own score and request spirometry from their physician if their score warranted it. The CAT scores from two previous studies have therefore been evaluated. The aim of the first study was to determine whether patients being treated for winter bronchitis in primary care included a proportion of patients who had undiagnosed COPD, and the second was designed to determine whether a proportion of patients being seen in cardiovascular disease clinics had airflow limitation that could be detected by the CAT.

\section{Materials and methods}

In study 1, patients were recruited consecutively between February 2012 and April 2012 at 15 centers in Japan. In study 2, patients were recruited consecutively between 2012 and 2013 at 17 centers in Japan. All patients gave written informed consent prior to any study-related procedures, and the protocol was approved by the appropriate institutional review boards.

Study 1 (GlaxoSmithKline [GSK] study code RES116549) was a screening survey to assess the rates of undiagnosed COPD in patients aged $\geq 40$ years. Entry criteria included the need for recurrent antitussives and/or antibiotics for two or more chest infections in the last 2 years in current or exsmokers with a $\geq 10$-pack-year smoking history. Patients with any diagnosed respiratory disease were excluded, as were patients with an acute respiratory event within 4 weeks prior to screening. Patients were not allowed to have taken any bronchodilator within 24 hours of the spirometry test. The data from this study regarding the symptoms of patients with undiagnosed airflow limitation have already been published. ${ }^{8}$

Study 2 (GSK study code RES116883) was a multicenter prospective study in patients who routinely visited a clinic for their cardiovascular disease. Patients who were aged $\geq 40$ years and had a smoking history completed the CAT and spirometry.

In both studies, assessments were performed at a single visit. Patients completed a CAT questionnaire. Each item was scored on a 6-point scale ranging from 0 to 5 . The total score can thus range from 0 to 40 , with higher scores representing greater impairment. Lung function was measured following the CAT using a hand-held spirometer (Hi-Checker; Takara Tsusho, Tokyo, Japan). The Hi-Checker has been previously demonstrated to be an accurate alternative to the conventional spirometer. ${ }^{8} \mathrm{FEV}_{1}$ and $\mathrm{FEV}_{6}$ were measured prior to bronchodilator use. Subjects performed forced expiration for 6 seconds until reproducible $\mathrm{FEV}_{6}$ values were obtained (the difference between the two highest $\mathrm{FEV}_{6}$ values was not more than $0.10 \mathrm{~L}$ ). Predicted FEV 1 values were calculated according to the formula used by the Lung Physiology Committee, Japanese Respiratory Society. ${ }^{12}$

Airflow limitation was defined as an $\mathrm{FEV}_{1} / \mathrm{FEV}_{6}$ ratio $<0.73^{13}$. The $\mathrm{FEV}_{1} / \mathrm{FEV}_{6}$ ratio can be used as a valid alternative for $\mathrm{FEV}_{1} / \mathrm{FVC}$ in the diagnosis of airway obstruction, especially for screening purposes in high-risk populations for COPD in primary care. ${ }^{13}$

\section{Statistical analysis}

All data were processed and summarized by the use of SAS version 9.2 or higher. The percentage of patients who had a CAT score and airflow limitation versus those with a CAT score and no airflow limitation was analyzed by $\chi^{2}$ test. Other variables were analyzed by analysis of variance. A regression analysis between the CAT score and $\mathrm{FEV}_{1} / \mathrm{FEV}_{6}$ ratio was performed. False-negative and false-positive values were also calculated to give the sensitivity and specificity of CAT scores $7-10$.

\section{Results}

A total of 3,062 patients - 2,067 in study 1 and 995 in study 2 - had a CAT score available. The mean age ( \pm standard deviation) of patients was $61.5( \pm 11)$ years, and patients were predominantly male $(88.8 \%)$. The characteristics are shown in Table 1.

Airflow limitation was found in 400 patients (19.4\%) and 269 patients $(27 \%)$ in studies 1 and 2 , respectively (Table 1 ). Of these, only $1.6 \%$ had a previous diagnosis of 
Table I Patient baseline characteristics (total patients screened and by study)

\begin{tabular}{|c|c|c|c|}
\hline & $\begin{array}{l}\text { Total } \\
(n=3,062)\end{array}$ & $\begin{array}{l}\text { Study I } \\
(n=2,067)\end{array}$ & $\begin{array}{l}\text { Study } 2 \\
(n=995)\end{array}$ \\
\hline \multicolumn{4}{|l|}{ Age, years } \\
\hline Mean (SD) & $61.5(11.6)$ & $59.0(11.6)$ & $66.6(10.0)$ \\
\hline \multicolumn{4}{|l|}{ Sex } \\
\hline Male & $88.8 \%$ & $85.5 \%$ & $95.5 \%$ \\
\hline \multicolumn{4}{|l|}{ Smoking history } \\
\hline Current & $44.9 \%$ & $53.4 \%$ & $27.4 \%$ \\
\hline Ex & $55.1 \%$ & $46.6 \%$ & $72.6 \%$ \\
\hline \multicolumn{4}{|l|}{ Smoking, pack-years } \\
\hline Mean (SD) & $37.3(23.5)$ & $34.6(21.6)$ & $43.1(26.1)$ \\
\hline \multicolumn{4}{|l|}{$\mathrm{BMI}$} \\
\hline Mean (SD) & $24.1(3.4)$ & $23.9(3.3)$ & $24.6(3.5)$ \\
\hline \multicolumn{4}{|c|}{ Diagnosed with COPD } \\
\hline Yes & $1.6 \%$ & 0 & $4.8 \%$ \\
\hline \multicolumn{4}{|l|}{ Chronic sputum* } \\
\hline Yes & $19.7 \%$ & $19.4 \%$ & $20.4 \%$ \\
\hline \multicolumn{4}{|l|}{ FEV } \\
\hline Mean (SD) & $2.52(0.76)$ & $2.63(0.76)$ & $2.29(0.70)$ \\
\hline \multicolumn{4}{|l|}{$\mathrm{FEV}_{6}$} \\
\hline Mean (SD) & $3.21(0.86)$ & $3.33(0.88)$ & $2.97(0.79)$ \\
\hline \multicolumn{4}{|l|}{ Airflow limitation } \\
\hline $\mathrm{FEV}_{1} / \mathrm{FEV}_{6}<0.73$ & $21.8 \%$ & $19.4 \%$ & $27.0 \%$ \\
\hline $\mathrm{FEV}_{1} / \mathrm{FEV}_{6} \geq 0.73$ & $78.2 \%$ & $80.6 \%$ & $73.0 \%$ \\
\hline \multicolumn{4}{|l|}{ CAT score } \\
\hline Mean (SD) & $7.4(5.9)$ & $7.6(5.9)$ & $6.9(5.8)$ \\
\hline
\end{tabular}

Note: *Chronic sputum was diagnosed as sputum symptoms observed for at least 3 months of the year for more than 2 consecutive years.

Abbreviations: SD, standard deviation; BMI, body mass index; COPD, chronic obstructive pulmonary disease; $\mathrm{FEV}_{\mathrm{l}}$, forced expiratory volume in I second $\mathrm{FEV}_{6}$, forced expiatory volume in 6 seconds; CAT, COPD Assessment Test.

$\operatorname{COPD}(0 \%$ in study 1 and $4.8 \%$ in study 2$)$. The CAT score in patients with airflow limitation was significantly higher than in patients without airflow limitation in both studies: $8.6(95 \%$ confidence interval [CI] 7.9-9.2) versus 7.4 (95\% CI 7.1-7.6) in study $1(P<0.001)$ and $8.3(95 \%$ CI $7.5-9.2)$ versus 6.4 (95\% CI 6.0-6.8) in study $2(P<0.001)$ (Figure 1$)$.

The demographics of patients in each CAT category are shown in Table 2. CAT score by age is shown in Figure 2. The degree of airflow limitation was significantly higher in patients with a higher CAT score (Table 2), eg, 19.6\% of patients who had a CAT score between 0 and 9 had an $\mathrm{FEV}_{1} /$ $\mathrm{FEV}_{6}$ ratio $<0.73$ compared with $33.8 \%$ of patients who had a CAT score between 20 and $29(P<0.001)$. The number of patients with a previous diagnosis of COPD and the number of patients with chronic sputum significantly increased with worsening CAT score (Table 2). This was not however seen in patients in the highest CAT category (CAT 30+), as there were only six patients with airflow limitation in this group.

A summary of lung-function data for patients with and without airflow obstruction is shown in Table 3. The mean

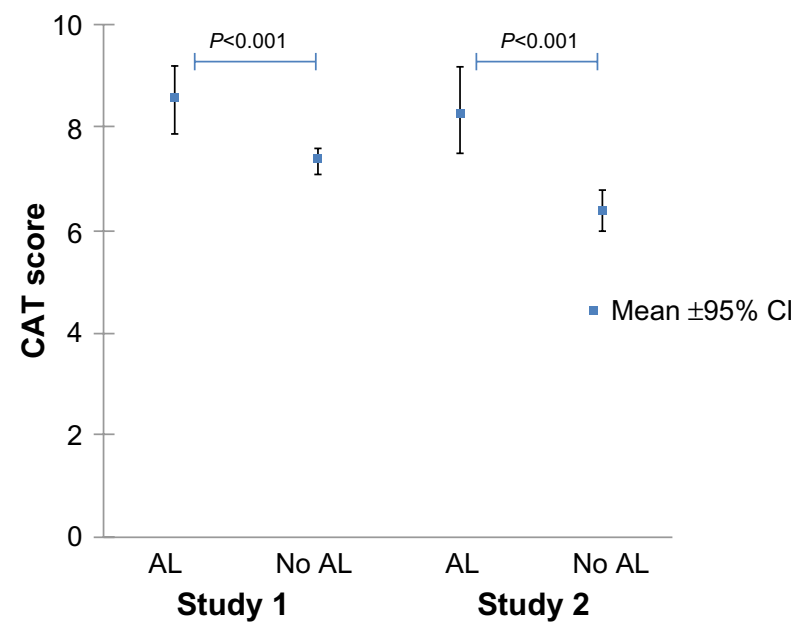

Figure I CAT score in patients with airflow limitation $(A L)$ and without AL. Abbreviations: COPD, chronic obstructive pulmonary disease; CAT, COPD Assessment Test; $\mathrm{Cl}$ confidence interval.

$\mathrm{FEV}_{1}$ in patients with airflow limitation and repeated chest infections in study 1 was $2.0 \mathrm{~L}$, and in the corresponding patients with cardiovascular disease in study 2 it was $1.7 \mathrm{~L}$. In patients without airflow limitation, these values were $2.8 \mathrm{~L}$ and $2.5 \mathrm{~L}$, respectively.

The percentage of patients with airflow limitation categorized by CAT score is shown in Figure 3. The majority of patients with airflow limitation had a CAT score $>7$. The sensitivity and specificity of the CAT at different CAT cut points is shown in Table 4. It can be seen that the false-positive rate remained constant across the cut points selected, but the false-negative rate fell to $31 \%$ with a CAT of 10 compared to $66 \%$ with a CAT of 7 .

\section{Discussion}

Data from these studies show that in patients aged $>40$ years with a smoking history and repeated chest infections or history of cardiovascular disease, the CAT has the potential to identify which patients should undergo spirometry. This confirms findings from another study performed using the CAT in the Middle East to identify people at risk for COPD in the general population. ${ }^{14}$

COPD screening with questionnaires and pulmonary function testing have been found to be useful methods for the early detection and treatment of COPD ${ }^{15}$ Another questionnaire that has been successfully utilized to screen for COPD patients in Japan is the 11-Q, which consists of eleven items, including smoking status, age, cough, phlegm, and shortness of breath. ${ }^{16}$ Other diagnostic COPD-screening tools include the Lung Function Questionnaire ${ }^{17}$ and the COPD Population Screener. ${ }^{18}$ These are specific instruments for screening 
Table 2 Characteristics of the population in each CAT category (studies I and 2 combined)

\begin{tabular}{|c|c|c|c|c|c|c|}
\hline & $\begin{array}{l}\text { Total } \\
(n=3,062)\end{array}$ & $\begin{array}{l}\text { CAT 0-9 } \\
(n=2,141)\end{array}$ & $\begin{array}{l}\text { CAT } 10-19 \\
(n=785)\end{array}$ & $\begin{array}{l}\text { CAT 20-29 } \\
(n=130)\end{array}$ & $\begin{array}{l}\text { CAT } \geq 30 \\
(n=6)\end{array}$ & $P$-value \\
\hline \multicolumn{7}{|l|}{ Age } \\
\hline Mean (SD) & $61.5(11.6)$ & $62.0(11.5)$ & $60.1(11.8)$ & $62.4(11.6)$ & $67.7(6.4)$ & $0.00 I^{*}$ \\
\hline \multicolumn{7}{|l|}{ Sex } \\
\hline Male, \% & $88.8 \%$ & $89.0 \%$ & $89.0 \%$ & $83.8 \%$ & $83.3 \%$ & $0.322 * *$ \\
\hline \multicolumn{7}{|l|}{ Smoking history } \\
\hline Current (\%) & $44.9 \%$ & $40.3 \%$ & $40.3 \%$ & $57.7 \%$ & $33.3 \%$ & $0.00 I^{* *}$ \\
\hline Ex $(\%)$ & $55.1 \%$ & $59.7 \%$ & $59.7 \%$ & $42.3 \%$ & $66.7 \%$ & \\
\hline \multicolumn{7}{|l|}{ Smoking, pack-years } \\
\hline Mean (SD) & $37.3(23.5)$ & $36.5(23.1)$ & $36.5(23.1)$ & $43.5(29.5)$ & $33.0(17.7)$ & $0.003^{*}$ \\
\hline \multicolumn{7}{|l|}{ BMI } \\
\hline Mean (SD) & $24.2(3.4)$ & $24.1(3.3)$ & $24.1(3.3)$ & $24.4(3.8)$ & $24.5(3.9)$ & $0.322^{*}$ \\
\hline \multicolumn{7}{|c|}{ Diagnosed with COPD } \\
\hline Diagnosed & $1.6 \%$ & $1.2 \%$ & $2.0 \%$ & $5.4 \%$ & $0.0 \%$ & $0.00 I^{* *}$ \\
\hline \multicolumn{7}{|l|}{ Chronic sputum } \\
\hline Yes & $19.7 \%$ & $13.7 \%$ & $31.6 \%$ & $46.2 \%$ & $33.3 \%$ & $0.00 I^{* *}$ \\
\hline \multicolumn{7}{|l|}{ FEV } \\
\hline Mean (SD) & $2.52(0.76)$ & $2.54(0.74)$ & $2.53(0.79)$ & $2.19(0.87)$ & $2.17(0.77)$ & $0.00 I^{*}$ \\
\hline \multicolumn{7}{|l|}{$\mathrm{FEV}_{6}$} \\
\hline Mean (SD) & $3.21(0.87)$ & $3.22(0.86)$ & $3.32(0.87)$ & $2.88(0.97)$ & $2.7 \mid(0.97)$ & $0.00 I^{*}$ \\
\hline \multicolumn{7}{|l|}{ Airflow limitation } \\
\hline $\mathrm{FEV}_{1} / \mathrm{FEV}_{6}<0.73$ & $21.8 \%$ & $19.6 \%$ & $26.0 \%$ & $33.8 \%$ & $16.7 \%$ & $0.00 I^{* *}$ \\
\hline $\mathrm{FEV}_{1} / \mathrm{FEV}_{6} \geq 0.73$ & $78.2 \%$ & $81.4 \%$ & $74.0 \%$ & $66.2 \%$ & $83.3 \%$ & \\
\hline \multicolumn{7}{|l|}{ CAT score } \\
\hline Mean (SD) & $7.4(5.9)$ & $4.2(2.7)$ & $13.1(2.5)$ & $23.1(2.7)$ & $35.3(4.1)$ & \\
\hline
\end{tabular}

Notes: *Analysis of variance; ** $\chi^{2}$. P-value calculated for comparison between the CAT categories.

Abbreviations: SD, standard deviation; BMI, body mass index; COPD, chronic obstructive pulmonary disease; FEV ${ }_{1}$, forced expiratory volume in I second; FEV ${ }_{6}$, forced expiatory volume in 6 seconds; CAT, COPD Assessment Test.

for COPD, unlike the CAT, which is an assessment and monitoring tool. However, the potential advantage of the CAT as a case-finding instrument is that doctors in routine care would only need one instrument for multiple purposes, thereby potentially reducing the barriers to finding patients with COPD.

The purpose of this analysis was to identify a CAT score that would reasonably suggest spirometry is required to confirm or otherwise a diagnosis of COPD. We combined data from two studies to increase statistical power and increase heterogeneity in the study populations. The Hi-Checker spirometer was used, since it is inexpensive and convenient for checking $\mathrm{FEV}_{1}$ and obstructive lung disorders. ${ }^{8}$ It has been shown to correlate with conventional spirometry, ${ }^{8,19}$ although one study showed that it did not produce identical results to a conventional spirometer. ${ }^{20}$ In both of these studies, a large number of previously undiagnosed patients were identified as having airflow limitation, defined as an $\mathrm{FEV}_{1} /$ $\mathrm{FEV}_{6}$ ratio $<0.73 .{ }^{13} \mathrm{~A}$ total of $21.8 \%$ of subjects were identified, of whom only $1.6 \%$ had a previous diagnosis of COPD. In study 1 , in patients presenting to the clinic with winter bronchitis and recurrent chest infections, airflow limitation was seen in $19.4 \%$ of the population. ${ }^{21}$ In study $2,27 \%$ of patients attending a cardiovascular clinic had airflow limitation, of whom $4.8 \%$ had a previous diagnosis of COPD. ${ }^{8}$ This confirms the high level of undiagnosed COPD in Japan reported in previous studies, ${ }^{4-6}$ such as the Nippon COPD Epidemiology study, which showed a prevalence of $10.9 \%$ in subjects aged $\geq 40$ years. ${ }^{4}$ We acknowledge that the lack of postbronchodilator lung-function data is a limitation in these studies.

In the patients with airflow limitation, the CAT score was 8.6 and 8.3 in studies 1 and 2, respectively, compared to 7.4 and 6.4 , respectively, in patients without airflow limitation. These scores are similar to those reported in healthy Japanese workers (some of whom were also found to have had airflow limitation). ${ }^{22}$ This score is lower than that seen in patients previously diagnosed with COPD in Europe,${ }^{11}$ and suggests that patients in our studies had not been diagnosed previously because they had a low level of symptoms when stable. This conclusion is compatible with a previous observation that patients who had COPD diagnosed through a spirometry screening program had much lower St George's Respiratory Questionnaire scores 


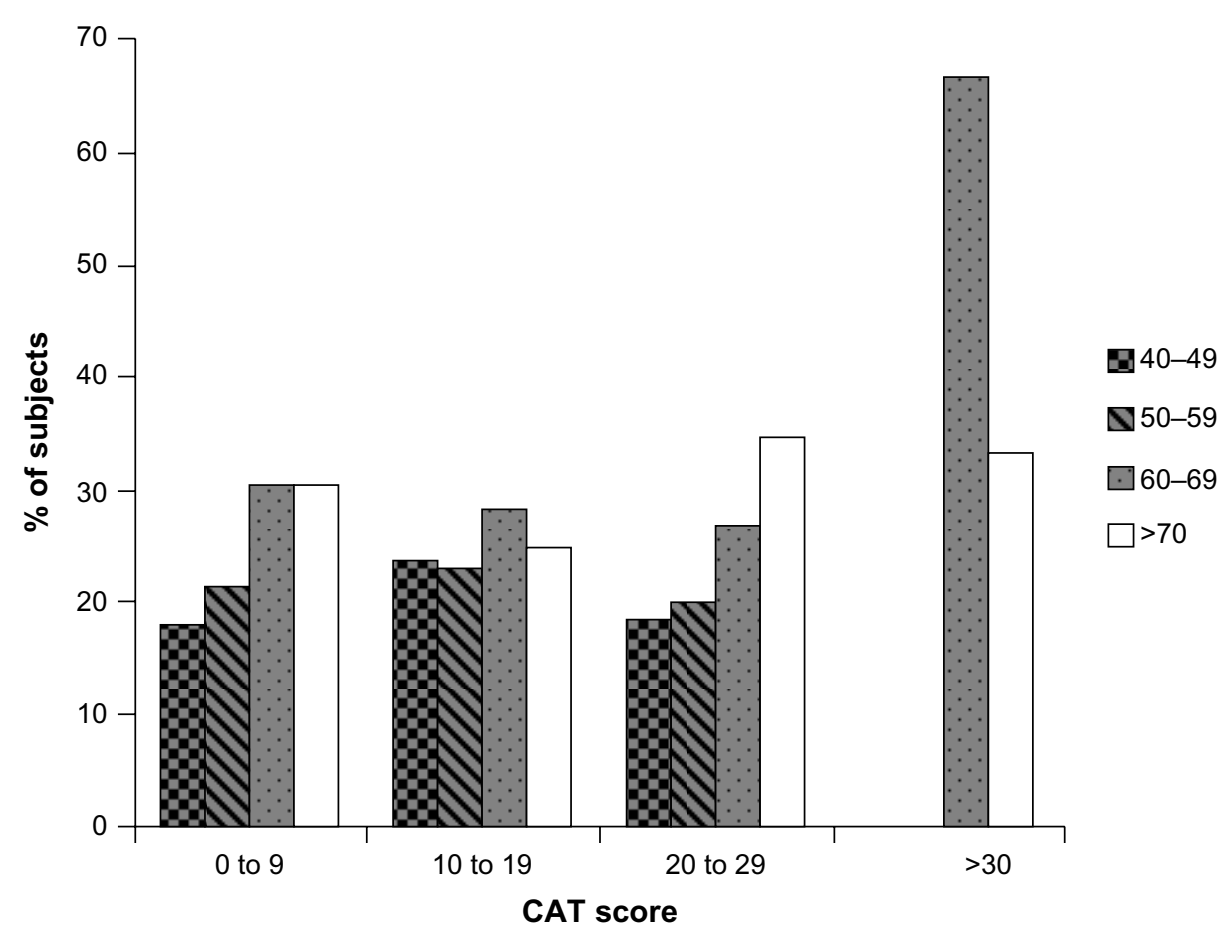

Figure 2 CAT score by age (years).

Abbreviations: COPD, chronic obstructive pulmonary disease; CAT, COPD Assessment Test.

than those with a previous physician's diagnosis of COPD. ${ }^{22}$ Health status and level of physical activity are not only markers of health but also predictors of survival in patients with COPD ${ }^{23-25}$; even COPD patients with GOLD ( Global initiative for chronic Obstructive Lung Disease) grade 1 disease have an increased risk of mortality, so it is important to find and treat these patients. ${ }^{26}$ It has also been shown that subjects with higher CAT scores were more likely to report recent exacerbations, ${ }^{10}$ so the CAT may also have a potential role as a case-finding tool to identify people at greater risk of exacerbation and hospitalization.

The choice of cut points always involves value judgments, in terms of the balance between sensitivity and efficacy (due to false-positive rates). Such judgments will also be influenced by the application to which an instrument is being used, eg, whether it is to be used to make a definitive

Table 3 Summary of lung-function data for patients with and without airflow limitation from both studies

\begin{tabular}{|c|c|c|c|c|c|c|c|}
\hline & $\begin{array}{l}\text { Total } \\
(n=3,062)\end{array}$ & $\begin{array}{l}\text { Study I } \\
(n=2,067)\end{array}$ & $\begin{array}{l}\text { Study } 2 \\
(n=995)\end{array}$ & $\begin{array}{l}\text { FEV }_{1} / \text { FEV }_{6}<0.73 \\
\text { Study I } \\
(\mathrm{n}=400)\end{array}$ & $\begin{array}{l}\text { FEV }_{1} / \mathrm{FEV}_{6}<0.73 \\
\text { Study } 2 \\
(\mathrm{n}=269)\end{array}$ & $\begin{array}{l}\text { FEV }_{1} / \text { FEV }_{6} \geq 0.73 \\
\text { Study I } \\
(n=I, 667)\end{array}$ & $\begin{array}{l}\text { FEV }_{1} / F V_{6} \geq 0.73 \\
\text { Study } 2 \\
(n=726)\end{array}$ \\
\hline \multicolumn{8}{|l|}{$\mathrm{FEV}_{1}$} \\
\hline Mean & 2.523 & 2.634 & 2.292 & 2.007 & 1.776 & 2.784 & 2.483 \\
\hline SD & 0.7623 & 0.7642 & 0.7046 & 0.7095 & $0.645 I$ & 0.6976 & 0.6259 \\
\hline $95 \% \mathrm{Cl}$ & $2.49-2.55$ & $2.60-2.67$ & $2.25-2.33$ & $1.94-2.08$ & $1.60-1.85$ & $2.75-2.82$ & $2.44-2.53$ \\
\hline Median & 2.51 & 2.64 & 2.29 & 2.03 & 1.75 & 2.78 & 2.45 \\
\hline Min & 0.41 & 0.41 & 0.49 & 0.41 & 0.49 & 0.63 & 0.58 \\
\hline $\operatorname{Max}$ & 4.88 & 4.88 & 4.84 & 3.91 & 3.98 & 4.88 & 4.84 \\
\hline \multicolumn{8}{|l|}{$\mathrm{FEV}_{6}$} \\
\hline Mean & 3.21 & 3.33 & 2.97 & 3.08 & 2.79 & 3.39 & 3.03 \\
\hline SD & 0.87 & 0.88 & 0.79 & 0.94 & 0.81 & 0.85 & 0.77 \\
\hline $95 \% \mathrm{Cl}$ & $3.18-3.24$ & $3.29-3.37$ & $2.92-3.02$ & $2.98-3.17$ & $2.69-2.89$ & $3.35-3.44$ & $2.98-3.00$ \\
\hline Median & 3.19 & 3.31 & 2.95 & 3.11 & 2.82 & 3.37 & 3.00 \\
\hline Min & 0.60 & 0.60 & 0.74 & 0.60 & 0.92 & 0.83 & 0.74 \\
\hline Max & 6.49 & 6.49 & 6.31 & 5.52 & 5.47 & 6.49 & 6.31 \\
\hline
\end{tabular}

Abbreviations: $\mathrm{FEV}_{1}$, forced expiratory volume in I second; $\mathrm{FEV}_{6}$, forced expiatory volume in 6 seconds; SD, standard deviation; $\mathrm{Cl}$, confidence interval; Min, minimum; Max, maximum. 


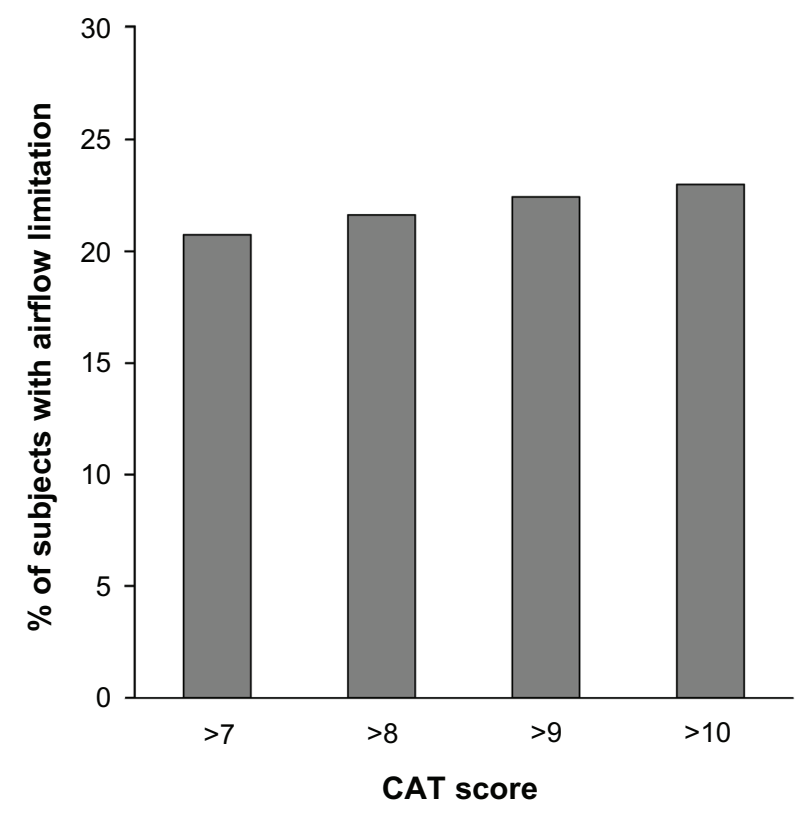

Figure 3 Percentage of patients with airflow limitation split by CAT score. Abbreviations: COPD, chronic obstructive pulmonary disease; CAT, COPD Assessment Test.

diagnosis or used as a case-finding tool to identify patients for whom another definitive test would be needed. This analysis explored the possible application of the CAT as a quick and economical case-finding tool, not as a diagnostic instrument, so a high level of efficiency would not be expected. The false-positive rate remained constant across a range of potential cut points, and a CAT score of 10 seems to provide a reasonable compromise, with the added convenience that it is also the threshold recommended by GOLD for introducing maintenance symptomatic treatment, so practitioners would only need to remember one CAT score for two purposes. There may be a concern about the use of the CAT to identify cases of COPD in cardiac disease clinics, because of shared symptoms that might result in an unacceptably high false-positive rate; however, that is unlikely to be the case. Two studies with the CAT have shown that cardiovascular comorbidity in COPD patients has little or no effect on the CAT score. ${ }^{27,28}$

Table 4 Calculated false-negative and false-positive values and the sensitivity and specificity of CAT scores 7-10

\begin{tabular}{lllll}
\hline & $\begin{array}{l}\text { False } \\
\text { negative }\end{array}$ & $\begin{array}{l}\text { False } \\
\text { positive }\end{array}$ & Sensitivity & Specificity \\
\hline CAT 7 & $66.2 \%$ & $75.8 \%$ & 0.517 & 0.548 \\
CAT 8 & $52.1 \%$ & $74.8 \%$ & 0.474 & 0.607 \\
CAT 9 & $39.8 \%$ & $73.9 \%$ & 0.419 & 0.669 \\
CAT 10 & $31.4 \%$ & $73.0 \%$ & 0.372 & 0.719 \\
\hline
\end{tabular}

Abbreviations: COPD, chronic obstructive pulmonary disease; CAT, COPD Assessment Test.
In conclusion, early detection of COPD is still an unresolved issue in Japan, as elsewhere in the world. In a study by Omori et al, ${ }^{7}$ it was shown that early stages of COPD can be detected on medical checkup in Japan. Use of the CAT as a case-finding tool may assist this process by identifying people who need spirometry for possible diagnosis of COPD, especially smokers with cardiovascular disease and patients with frequent episodes of acute bronchitis.

\section{Acknowledgments}

We are grateful to the medical institutes who participated in this study, and to the Center for Clinical Trials, Japan Medical Association. We are also grateful to all teams of GSK for their contribution to this study. The authors thank Diana Jones (Cambrian Clinical Associates Limited) for medical writing and manuscript coordination, which was funded by the study sponsor. GSK was the funding source, and was involved in all stages of the study-protocol development. GSK also took in charge all costs associated with the development and the publishing of the present manuscript; authors who were not GSK employees did not receive payment for writing this paper. All authors had final responsibility for submitting this paper for publication.

\section{Disclosure}

DY is an employee of GSK and reports ownership of GSK stock options. YN discloses that he has received payment from the commercial entity sponsoring the study for lectures. KO discloses no conflict of interest. GH discloses having received consultancy fees from GSK and reports ownership of GSK stock options. PJ discloses that his university has received honoraria and research grants from the commercial entity that sponsored the study.

\section{References}

1. Global initiative for chronic Obstructive Lung Disease (GOLD). Global Strategy for the Diagnosis, Management, and Prevention of COPD. Bethesda (MD): GOLD; 2011.

2. Murray CJ, Lopez AD. Alternative projections of mortality and disability by cause 1990-2020: Global Burden of Disease Study. Lancet. 1997;349:1498-1504.

3. Lopez AD, Shibuya K, Rao C, et al. Chronic obstructive pulmonary disease: current burden and future projections. Eur Respir J. 2006;27: 397-412.

4. Fukuchi Y, Nishimura M, Ichinose M, et al. COPD in Japan: the Nippon COPD Epidemiology study. Respirology. 2004;9:458-465.

5. Fukahori S, Matsuse H, Takamura N, et al. Prevalence of chronic obstructive pulmonary diseases in general clinics in terms of $\mathrm{FEV}_{1} / \mathrm{FVC}$. Int $J$ Clin Pract. 2009;63:269-274.

6. Takahashi T, Ichinose M, Inoue H, Shirato K, Hattori T, Takishima T. Underdiagnosis and undertreatment of COPD in primary care settings. Respirology. 2003;8:504-508. 
7. Omori H, Nonami Y, Mihara S, Marubayashi T, Morimoto Y, Aizawa H. Prevalence of airflow limitation on medical check-up in Japanese subjects. J UOEH. 2007;29:209-219.

8. Onishi K, Yoshimoto D, Hagan GW, Jones PW. Prevalence of airflow limitation in outpatients with cardiovascular diseases in Japan. Int $J$ Chron Obstruct Pulmon Dis. 2014;9:563-568.

9. Agustí A, Soler JJ, Molina J, et al. Is the CAT questionnaire sensitive to changes in health status in patients with severe COPD exacerbations? COPD. 2012;9:492-498.

10. Jones P, Harding G, Wiklund I, Berry P, Leidy N. Improving the process and outcome of care in COPD: development of a standardised assessment tool. Prim Care Respir J. 2009;18:208-215.

11. Jones PW, Harding G, Berry P, Wiklund I, Chen WH, Leidy NK. Development and first validation of the COPD Assessment Test. Eur Respir J. 2009;34:648-654.

12. Japanese Respiratory Society. Guidelines for the Diagnosis and Treatment of COPD. 3rd ed. Tokyo: Japanese Respiratory Society; 2009.

13. Vandevoorde J, Verbanck S, Schuermans D, Kartounian J, Vincken W. $\mathrm{FEV}_{1} / \mathrm{FEV}_{6}$ and $\mathrm{FEV}_{6}$ as an alternative for $\mathrm{FEV}_{1} / \mathrm{FVC}$ and $\mathrm{FVC}$ in the spirometric detection of airway obstruction and restriction. Chest. 2005;127:1560-1564.

14. Jones PW, Shahrour N, Nejjari C, et al. Psychometric evaluation of the COPD assessment test: data from the BREATHE study in the Middle East and North Africa region. Respir Med. 2012;106:S86-S99.

15. Oike T, Senjyu H, Higa N, et al. Detection of airflow limitation using the 11-Q and pulmonary function tests. Intern Med. 2013;52:887-893.

16. Kida K, Wakabayashi R, Mizuuchi T, Murata A. Screening for suspected chronic obstructive pulmonary disease with an eleven item pre-interview questionnaire (11-Q). Intern Med. 2006;45:1201-1207.

17. Hanania NA, Mannino DM, Yawn BP, et al. Predicting risk of airflow obstruction in primary care: validation of the lung function questionnaire (LFQ). Respir Med. 2010;104:1160-1170.

18. Martinez FM, Raczek AE, Seifer FD, et al. Development and initial validation of a self-scored COPD Population Screener Questionnaire (COPD-PS). COPD. 2008;5:85-95.
19. Kozaki M, Shimauchi M, Yatera K, et al. Correlation of FEV,$F_{1} V_{1}$ / $\mathrm{FEV}_{6}$, and $\mathrm{FEV}_{1} \%$ between poreg, (Hi Checker) and conventional spirometer. Chest. 2011;140:576A.

20. Nishimura K, Nakayasu K, Kobayashi A, Mitsuma S. Case identification of subjects with airflow limitations using the handheld spirometer "Hi-Checker"TM": comparison against an electronic desktop spirometer. COPD. 2011;8:450-455.

21. Nakano Y, Nagai A, Mishima M, Yoshimoto D, Hagan G. [Investigation of COPD management in primary care in Japan using hand-held spirometer]. Japan Med Assoc J. 2013;142:1093-1098. Japanese.

22. Nishimura K, Mitsuma S, Kobayashi A, et al. COPD and disease-specific health status in a working population. Respir Res. 2012;14:61

23. Miravitlles M, Soriano JB, García-Río F, et al. Prevalence of COPD in Spain: impact of undiagnosed COPD on quality of life and daily life activities. Thorax. 2009;64:863-868.

24. Domingo-Salvany A, Lamarca R, Ferrer M, et al. Health-related quality of life and mortality in male patients with chronic obstructive pulmonary disease. Am J Respir Crit Care Med. 2002;166:680-685.

25. Garcia-Aymerich J, Lange P, Benet M, Schnohr P, Antó JM. Regular physical activity modifies smoking-related lung function decline and reduces risk of chronic obstructive pulmonary disease: a population-based cohort study. Am J Respir Crit Care Med. 2007; 175:458-463.

26. Mannino DM, Doherty DE, Sonia Buist A. Global Initiative on Obstructive Lung Disease (GOLD) classification of lung disease and mortality: findings from the Atherosclerosis Risk in Communities (ARIC) study. Respir Med. 2006;100:115-122.

27. Jones PW, Brusselle G, Dal Negro RW, et al. Properties of the COPD assessment test in a cross-sectional European study. Eur Respir J. 2011;38:29-35

28. Mackay AJ, Donaldson GC, Patel AR, Jones PW, Hurst JR, Wedzicha JA. Usefulness of the Chronic Obstructive Pulmonary Disease Assessment Test to evaluate severity of COPD exacerbations. Am J Respir Crit Care Med. 2012;185:1218-1224.
International Journal of COPD

\section{Publish your work in this journal}

The International Journal of COPD is an international, peer-reviewed journal of therapeutics and pharmacology focusing on concise rapid reporting of clinical studies and reviews in COPD. Special focus is given to the pathophysiological processes underlying the disease, intervention programs, patient focused education, and self management protocols.

\section{Dovepress}

This journal is indexed on PubMed Central, MedLine and CAS. The manuscript management system is completely online and includes a very quick and fair peer-review system, which is all easy to use. Visit http://www.dovepress.com/testimonials.php to read real quotes from published authors. 